\title{
Isolation and Structural Elucidation of Hemolysin from the Phytoflagellate Prymnesium parvum
}

\author{
Hiroshi KozaKaI, Yasukatsu Oshima and Takeshi Yasumoto \\ Department of Food Chemistry, Faculty of Agriculture, \\ Tohoku University, Tsutsumi-dori, Sendai 980, Japan \\ Received July 16, 1981
}

\begin{abstract}
Hemolysin in the phytoflagellate Prymnesium parvum was separated into six components by thin layer chromatography. The major component named hemolysin I was isolated and identified as a mixture of $1^{\prime}$ - $O$-octadecatetraenoyl-3'- $O$-(6- $O-\beta$-D-galactopyranosyl- $\beta$-D-galactopyranosyl)glycerol (1) and $1^{\prime}$ - $O$-octadecapentaenoyl-3'- $O$-(6- $O$ - $\beta$-D-galactopyranosyl- $\beta$-D-galactopyranosyl)-glycerol (2).
\end{abstract}

The phytoflagellate Prymnesium parvum is notorious for producing toxins with ichthyotoxic and hemolytic activities and thus bringing about mass mortality of fish in brackish water culture ponds. ${ }^{1,2)}$ Though the chemical properties of the toxins have been studied by several workers, the conclusions of the past works are contradictory and confusing. Paster ${ }^{3)}$ presumed the toxin to be a glycolipid while Ulitzur and Shilo ${ }^{4)}$ described it as a proteolipid. The present study was undertaken to clarify the discrepancy of the past works.

Cells of $P$. parvum harvested from 1500 liters $\left(9.8 \times 10^{11}\right.$ cells $)$ of unialgal culture were extracted with methanol. After evaporation of methanol the concentrate was diluted with water and extracted with diethyl ether and 1butanol. Six hemolytic components (hemolysin $\mathrm{I} \sim \mathrm{VI}$ ) were present in both the organic phases when the residues were analyzed by thin layer chromatography and sprayed with mouse erythrocyte suspension. Among the six hemolysins only hemolysin I with the highest $R f$ value gave a distinct spot when charred with sulfuric acid, indicating its abundance in quantity. Therefore, the hemolysin I was isolated and its chemical structure was determined.

Treatments of the extracts with two silicic acid columns and with two reversed phase columns afforded $30 \mathrm{mg}$ of colorless waxy solid of hemolysin I which was homogeneous as judged by TLC. The IR spectrum of hemolysin I was reminiscent of glycolipid having strong bands due to hydroxyls (3400, 1070, 1160 $\left.\mathrm{cm}^{-1}\right)$, ester $\left(1725 \mathrm{~cm}^{-1}\right)$, and double bonds $\left(1650 \mathrm{~cm}^{-1}\right)$. Two hemiacetal carbons at 105.2 ppm and 13 carbons bearing oxygen from 62.4 to $76.6 \mathrm{ppm}$ in CMR spectrum also suggested the presence of sugar moiety. More affirmative evidence for sugars were obtained by fragment ions at $m / z 204,271,319$, and $361^{5)}$ in the mass spectrometry of its trimethylsilyl derivative. On the basis of these evidences hemolysin I was subjected to methanolysis and the products were analyzed by gas chromatography. The polar fraction of the methanolysis products gave galactose and glycerol in 1.5 to 1.0 molar ratio, while the nonpolar fraction gave two fatty acid methyl esters in 3.6 to 1.0 ratio. Upon catalytic hydrogenation both fatty acids gave a single peak having identical retention time with methyl stearate. Comparing their retention times with reference fatty acid methyl esters and literature values, the major component was identified as $\mathrm{C}_{18: 4}$ fatty acid and the minor one as $\mathrm{C}_{18: 5}$ acid. Since signals in CMR spectrum point to the presence of 33 carbons the above results indicate that hemolysin I is a mixture of two components composed of two mol of galactose, one mol of glycerol and one mol of either $\mathrm{C}_{18: 4}$ or $\mathrm{C}_{18: 5}$ fatty acid. The major component with $\mathrm{C}_{18: 4}$ 
fatty acid was designated hemolysin Ia and the minor one hemolysin Ib.

The anomeric $\beta$-configuration of the glycosidic bond was determined on the basis of the anomeric signal at $105.2 \mathrm{ppm}(2 \mathrm{C}){ }^{6)}$ This was consistent with the result of the enzymatic degradation experiment that one mol of galactose was liberated by $\beta$-galactosidase but not by $\alpha$-galactosidase. By comparing the chemical shifts with those of methyl- $\beta$-D-galactoside a signal at $62.4(\mathrm{t})$ was assigned to C-6 carbon of the terminal galactose. ${ }^{7)}$ If the two galactose residues are in $1 \rightarrow 6$ linkage, the C- 6 carbon of the inner galactose is expected to shift toward the down field by about $10 \mathrm{ppm}$. The presence of a signal at $71.8 \mathrm{ppm}$ and the fact that it gives a triplet by off-resonance decoupling measurement confirm $1 \rightarrow 6$ linkage.

The structure of the fatty acid moiety was elucidated mostly by PMR study. The absence of a significant absorption maximum in UV spectrum excludes the presence of conjugated double bonds. The lack of absorption at 965 $\mathrm{cm}^{-1}$ in IR spectrum along with the small coupling constant value $(8.0 \mathrm{~Hz})$ of olefinic protons supports that the double bonds are in cis form. Irradiation of the terminal methyl protons at $0.96 \mathrm{ppm}$ transformed the multiplet at $2.06 \mathrm{ppm}(4 \mathrm{H})$ into a doublet $(J=2.0 \mathrm{~Hz})$, confirming the presence of $\mathrm{C}-17$ methylene protons. The fact that this multiplet changes to a quartet $(J=7.4 \mathrm{~Hz})$ by irradiation at the olefinic protons proves that $\mathrm{C}-17$ methylene is located next to a double bond. The broad peak at $2.81 \mathrm{ppm}(6 \mathrm{H})$ which is coupled with olefinic protons indicates that three methylenes are sandwitched between four double bonds. Thus it may be reasonably concluded that the $C_{18: 4}$ fatty acid is cis-6, cis-9, cis-12, cis-15octadecatetraenoic acid and the $\mathrm{C}_{18: 5}$ acid cis3, cis-6, cis-9, cis-12, cis-15-octadecapentaenoic acid. The position of double bonds in $\mathrm{C}_{18: 5}$ acid was also supported by the signals at 33.6 and $132.7 \mathrm{ppm}$ in CMR assignable to $\mathrm{C}-2$ and $\mathrm{C}-3$, respectively. ${ }^{8)}$

In both PMR and CMR most of the signals derived from $\mathrm{Ib}$, were overlapped with those from Ia, except few minor signals due to an additional double bond in $\mathrm{C}_{18: 5}$ fatty acid of Ib. This confirms that Ib differs from Ia only in fatty acid moiety.

The position of attachment of fatty acid to glycerol was confirmed by mass spectrum of the trimethylsilyl derivative. The ion peaks at $m / z 259,289,391$, and 405 provide a rational basis for the structure shown in Fig. 1, in which the 2-position of glycerol is not substituted. ${ }^{9)}$

Thus all evidences above-cited allow us to assign the structure of hemolysin I $(\mathbf{1}, \mathbf{2})$.
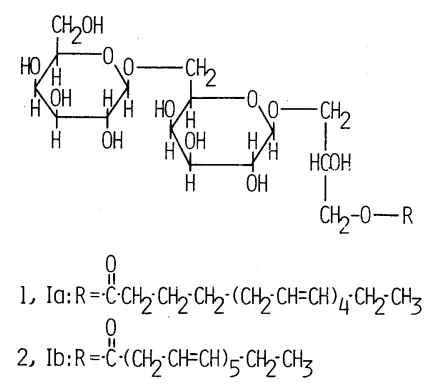

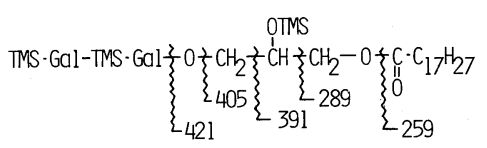

FIG. 1. Fragmentation of Trimethylsilyl Derivative of Hemolysin I by Mass Spectrometry.

Occurrence of compounds structurally related to hemolysin I is not unusual in the plant world: digalactosyl diglycerides are found in higher plants, mono- and digalactosyl diglycerides acylated exclusively with highly unsaturated fatty acids in a dinoflagellate Glenodinium sp., ${ }^{10)}$ and digalactosyl monoglyceride with palmitic acid in a green alga Ulva pertusa. ${ }^{11)}$ However, hemolysin $\mathrm{I}$ is distinct from these glycolipids by its $\beta$-galactosidic linkage, highly unsaturated nature of the fatty acids, and unsubstituted 2-position of glycerol. The chemical properties of hemoly$\sin \mathrm{II} \sim$ VI showing higher specific activity are the subjects for a future study.

\section{EXPERIMENTAL}

Instruments. NMR spectra were taken with a JEOL FX- 
100 spectrometer, IR spectra with JASCO IR-1 spectrometer, and UV spectra with a Hitachi 124 spectrophotometer, and optical rotation with a JASCO ORD/UV-5 spectrometer. Mass spectra of trimethylsilyl derivative of hemolysin I was measured with a Hitachi M 80 mass spectrometer. Gas-liquid chromatography was performed on a Hitachi 163 model gas chromatograph instrument equipped with hydrogen flame ionization detector.

Culture. Unialgal culture of $P$. parvum was grown in either $75 \%$ sea water medium enriched with $75 \%$ SW II supplement ${ }^{12)}$ or $50 \% \mathrm{ASP}_{12}$ medium $^{13)}$ at $20 \sim 25^{\circ} \mathrm{C}$ under illumination of $3000 \sim 5000$ lux for 3 weeks. The cultured cells were collected by constant flow centrifugation.

Purification procedures. The harvested cells were homogenized in $\mathrm{MeOH}$ at room temperature. The $\mathrm{MeOH}$ extracts were concentrated, diluted with water, and extracted first with $\mathrm{Et}_{2} \mathrm{O}$ and then with 1-BuOH. The residue in the organic phases were placed on a silicic acid column (Mallinckrodt, 100 mesh) and successively eluted with $\mathrm{CHCl}_{3}$ and $\mathrm{CHCl}_{3}-\mathrm{MeOH}$ mixtures with increasing stepwise $\mathrm{MeOH}$ contents. $\mathrm{CHCl}_{3}-\mathrm{MeOH}(9: 1)$ eluate which contained hemolysin I was further chromatographed on a silicic acid column (Silica gel 60, merck, 230 400 mesh, $0.8 \times 100 \mathrm{~cm}$ ) with $\mathrm{CHCl}_{3}-\mathrm{MeOH}-\mathrm{H}_{2} \mathrm{O}(90: 9: 1)$ by the use of a constant flow pump. The eluates were monitored by hemolytic test ${ }^{14)}$ and TLC. The final purification was carried out on medium pressure chromatographic systems employing the following conditions. System I: adsorbent, LiChroprep RP-2 (Merck); solvent, $\mathrm{MeOH}-\mathrm{H}_{2} \mathrm{O}$ (7:3); column, $0.5 \times 50 \mathrm{~cm}$; flow rate, $1 \mathrm{ml} / \mathrm{min}$; pressure, 20 $\mathrm{kg} / \mathrm{cm}^{2}$. System II: adsorbent, ODS (Kyowa Seimitsu); solvent, $\mathrm{MeOH}-\mathrm{H}_{2} \mathrm{O}(90: 10)$ and $(85: 5)$; column, $1 \times 50$ $\mathrm{cm}$; flow rate, $1 \mathrm{ml} / \mathrm{min}$; pressure, $35 \mathrm{~kg} / \mathrm{cm}^{2}$.

TLC was carried out on $0.25 \mathrm{~mm}$ precoated Silica gel 60 glass sheets (Merck) with the following two solvent systems: (1) $\mathrm{CHCl}_{3}-\mathrm{MeOH}-\mathrm{H}_{2} \mathrm{O}$ (75:25:4); (2) $\mathrm{CHCl}_{3}-$ $\mathrm{MeOH}-\mathrm{H}_{2} \mathrm{O}(55: 35: 8)$. Hemolysins were detected by spraying a suspension of mouse erythrocytes in $0.85 \%$ saline. Organic matters were visualized by spraying $50 \%$ $\mathrm{H}_{2} \mathrm{SO}_{4}$ in $\mathrm{MeOH}$. Homolysin I gave a single spot at $R f$ 0.53 by solvent (1) and at $R f 0.67$ by solvent (2).

Gas chromatography. To run GLC analysis hemolysin I was subjected to methanolysis by heating the dried sample in $5 \%$ methanolic hydrochloric acid at $90^{\circ} \mathrm{C}$ for $12 \mathrm{hr}$. The reaction mixture was extracted with hexane after addition of water. The methanol solubles were dried completely and trimethylsilylated with TRI SIL " $Z$ " (Pierce) to be analyzed on glass column $(3 \mathrm{~mm} \times 2 \mathrm{~m})$ packed with $10 \%$ SE-30 on Uniport B (60/80). The column temperature was maintained at $160^{\circ} \mathrm{C}$ or programmed from 100 to $200^{\circ} \mathrm{C}$ at $4^{\circ} \mathrm{C} / \mathrm{min}$, the upper limit being held until the last peak had emerged. Erythritol was used as an internal standard. The hexane extract was subjected to GLC analysis both di- rectly and after hydrogenation over palladium black for $6 \mathrm{hr}$. Three different glass columns $(3 \mathrm{~mm} \times 2 \mathrm{~m})$ were employed for fatty acids analysis: $15 \%$ DEGS on Chromosorb WAW DMCS $(60 / 80), 5 \%$ EGSS-X on Chromosorb WAW (60/80), and $10 \%$ SE-30 on Uniport B $(60 / 80)$. The first column was operated at $200^{\circ} \mathrm{C}$, the second at $180^{\circ} \mathrm{C}$, and the third at $220^{\circ} \mathrm{C}$. A mixture of standard fatty acid methyl esters (Gasukuro Kogyo) was used as the references and the ECL values were compared with those in literatures. ${ }^{15,16)}$

Enzymatic degradation. $\alpha$-Galactosidase (EC. 3.2.1.22) and $\beta$-galactosidase (EC. 3.2.1.23) (Sigma, from $A$. niger) were used. Hemolysin I was incubated in the following reaction mixtures: $290 \mu \mathrm{l}$ of $0.2 \mathrm{M} \mathrm{AcOH}-0.1 \mathrm{M} \mathrm{NaOH}$ buffer containing $0.5 \%$ Tween 60 (pH 5.5 for $\alpha$-galactosidase, $\mathrm{pH} 5.2$ for $\beta$-galactosidase), $10 \mu \mathrm{l}$ (0.067 unit) of enzyme solution. The reaction mixtures were kept at $23^{\circ} \mathrm{C}$ for $20 \mathrm{hr}$ after shaking sufficiently, diluted with $0.1 \mathrm{M}$ $\mathrm{NaOH}$ to $1 \mathrm{ml}$ and the reducing power of galactose enzymatically released from hemolysin I was determined according to the method of Park and Johnson. ${ }^{17)}$

Spectral data of hemolysin I. IR $v_{\max }^{\mathrm{CHCl}_{3}} \mathrm{~cm}^{-1}: 3400(\mathrm{OH})$, 1070, 1160(C-O), $1725(\mathrm{COOR})$, and $1650(\mathrm{C}=\mathrm{C}) .[\alpha]_{\mathrm{D}}^{23}$ $+0.17(c=0.003, \mathrm{MeOH}) . \mathrm{PMR} \delta_{\mathrm{Me}_{4} \mathrm{Si}}^{\mathrm{CD}_{3} \mathrm{OD}} \mathrm{ppm}: 0.96(3 \mathrm{H}, \mathrm{t}$, $J=7.4 \mathrm{~Hz}), 1.31(2 \mathrm{H}, \mathrm{tt}, J=5.2 \mathrm{~Hz}), 1.56(2 \mathrm{H}, \mathrm{tt}, J=$ $5.2 \mathrm{~Hz}), 2.06(2 \mathrm{H}, \mathrm{qd}, J=7.4,2.0 \mathrm{~Hz}, 2 \mathrm{H}, \mathrm{td}, J=5.2$, $2.0 \mathrm{~Hz}), 2.36(2 \mathrm{H}, \mathrm{t}, J=7.0 \mathrm{~Hz}), 2.81(6 \mathrm{H}, \mathrm{dd}, J=3.9 \mathrm{~Hz})$, $3.53 \sim 4.22(12 \mathrm{H}$, complex signals), $5.35(8 \mathrm{H}, \mathrm{dt}, J=8.0$, $3.9 \mathrm{~Hz}$ ). CMR $\delta_{\mathrm{Me}_{4} \mathrm{Si}}^{\mathrm{CH}_{3} \mathrm{OD}}$ ppm: $14.6(1 \mathrm{C}), 21.5(1 \mathrm{C}), 25.6(1 \mathrm{C})$, 26.4 (2C), 26.5 (1C), 27.8 (1C), 30.1 (1C), 34.8 (1C), 62.4 (1C), $66.5(2 \mathrm{C}), 69.6(1 \mathrm{C}), 70.2(2 \mathrm{C}), 71.8(1 \mathrm{C}), 72.5(2 \mathrm{C})$, 74.8 (2C), 76.6 (2C), 105.2 (2C), 129.0 (2C), 129.2 (2C), 129.4 (2C), 130.6 (2C), 175.2 (1C). Minor signals due to an additional double bond in Ib (2) were observed at 26.7 , 33.6, 128.1, and $132.7 \mathrm{ppm}$. Trimethylsilyl derivative of hemolysin I showed the following ions but molecular ion was not observed: $m / z$ 103, 117, 129, 146, 157 (base), 204, 217, 243, 259, 271, 289, 319, 333, 361, 391, 405, 421.

Acknowledgments. The authors wish to thank to Dr. L. Berger, University of Hawaii, for donating the seed culture of $P$. parvum. They are also grateful to the staffs of the Application Laboratory of Hitachi Co. for measuring the mass spectra.

\section{REFERENCES}

1) M. Shilo and R. F. Rosenberger, Ann. N.Y. Acad. Sci., 90, 866 (1960).

2) M. Shilo, Bacteriol. Rev., 31, 180 (1967).

3) Z. Paster, "Marine Pharmacognosy," ed. by D. F. Martin and G. M. Padilla, Academic Press, Inc., New York, 1973, pp. $241 \sim 263$.

4) S. Ulitzur and M. Shilo, Biochim. Biophys. Acta, 201, 
350 (1970).

5) D. C. DeJongh, T. Radford, J. D. Hribar, S. Hanessian, M. Bieber, G. Dawson and C. C. Sweely, J. Am. Chem. Soc., 91, 1728 (1969).

6) N. Yamaoka, T. Usui, K. Matsuda and K. Tuzimura, Tetrahedron Lett., 2047 (1971).

7) S. Seo, Y. Tomita, K. Tori and Y. Yoshimura, J. Am. Chem. Soc., 100, 3331 (1978).

8) J. G. Batchelor, R. J. Cushley and J. H. Prestegard, J. Org. Chem., 39, 1698 (1974).

9) G. Odham and E. Stenhagen, "Biochemical Application of Mass Spectrometry," ed. by G. R. Waller, John Wiley \& Sons, Inc., New York, 1972, pp. $229 \sim 249$.
10) G. M. Harrington, D. H. Beach, J. E. Dunham and G. G. Holz, Jr., J. Protozool., 17, 213 (1970).

11) N. Fusetani and Y. Hashimoto, Agric. Biol. Chem., 39, 2021 (1975).

12) H. Iwasaki, Biol. Bull., 121, 173 (1961).

13) L. Provasoli, J. J. A. Mclaughlin and M. R. Droop, Arch. Mikrobiol., 25, 392 (1957).

14) Y. Hashimoto and Y. Oshima, Toxicon, 10, 279 (1972).

15) J. D. Joseph, Lipids, 10, 395 (1975).

16) H. H. Hofstetter, N. Sen and R. T. Holman, J. Am. Chem. Soc., 42, 537 (1965).

17) M. Sugita, S. Shirai, O. Itasaka and T. Hori, $J$. Biochem., 77, 125 (1975). 